\title{
Implications of carbon saturation model structures for simulated nitrogen mineralization dynamics
}

\author{
C. M. White ${ }^{1}$, A. R. Kemanian ${ }^{2}$, and J. P. Kaye ${ }^{1}$ \\ ${ }^{1}$ Department of Ecosystem Science and Management, The Pennsylvania State University, 116 Agricultural Sciences and \\ Industries Building, University Park, PA 16802, USA \\ ${ }^{2}$ Department of Plant Science, The Pennsylvania State University, 116 Agricultural Sciences and Industries Building, \\ University Park, PA 16802, USA
}

Correspondence to: C. M. White (cmw29@psu.edu)

Received: 17 April 2014 - Published in Biogeosciences Discuss.: 20 June 2014

Revised: 13 October 2014 - Accepted: 22 October 2014 - Published: 5 December 2014

\begin{abstract}
Carbon (C) saturation theory suggests that soils have a limited capacity to stabilize organic $\mathrm{C}$ and that this capacity may be regulated by intrinsic soil properties such as clay concentration and mineralogy. While $\mathrm{C}$ saturation theory has advanced our ability to predict soil $\mathrm{C}$ stabilization, few biogeochemical ecosystem models have incorporated $\mathrm{C}$ saturation mechanisms. In biogeochemical models, $\mathrm{C}$ and nitrogen $(\mathrm{N})$ cycling are tightly coupled, with $\mathrm{C}$ decomposition and respiration driving $\mathrm{N}$ mineralization. Thus, changing model structures from non-saturation to $\mathrm{C}$ saturation dynamics can change simulated $\mathrm{N}$ dynamics. In this study, we used $\mathrm{C}$ saturation models from the literature and of our own design to compare how different methods of modeling $\mathrm{C}$ saturation affected simulated $\mathrm{N}$ mineralization dynamics. Specifically, we tested (i) how modeling $\mathrm{C}$ saturation by regulating either the transfer efficiency $\left(\varepsilon, \mathrm{g} \mathrm{C}\right.$ retained $\mathrm{g}^{-1} \mathrm{C}$ respired) or transfer rate $(k)$ of $\mathrm{C}$ to stabilized pools affected $\mathrm{N}$ mineralization dynamics, (ii) how inclusion of an explicit microbial pool through which $\mathrm{C}$ and $\mathrm{N}$ must pass affected $\mathrm{N}$ mineralization dynamics, and (iii) whether using $\varepsilon$ to implement $\mathrm{C}$ saturation in a model results in soil texture controls on $\mathrm{N}$ mineralization that are similar to those currently included in widely used non-saturating $\mathrm{C}$ and $\mathrm{N}$ models. Models were parameterized so that they rendered the same $\mathrm{C}$ balance. We found that when $\mathrm{C}$ saturation is modeled using $\varepsilon$, the critical $\mathrm{C}: \mathrm{N}$ ratio for $\mathrm{N}$ mineralization from decomposing plant residues $\left(r_{\mathrm{cr}}\right)$ increases as $\mathrm{C}$ saturation of a soil increases. When $\mathrm{C}$ saturation is modeled using $k$, however, $r_{\mathrm{cr}}$ is not affected by the $\mathrm{C}$ saturation of a soil. Inclusion of an explicit microbial pool in the model structure was neces-
\end{abstract}

sary to capture short-term $\mathrm{N}$ immobilization-mineralization turnover dynamics during decomposition of low $\mathrm{N}$ residues. Finally, modeling $\mathrm{C}$ saturation by regulating $\varepsilon$ led to similar soil texture controls on $\mathrm{N}$ mineralization as a widely used non-saturating model, suggesting that $\mathrm{C}$ saturation may be a fundamental mechanism that can explain $\mathrm{N}$ mineralization patterns across soil texture gradients. These findings indicate that a coupled $\mathrm{C}$ and $\mathrm{N}$ model that includes saturation can (1) represent short-term $\mathrm{N}$ mineralization by including a microbial pool and (2) express the effects of texture on $\mathrm{N}$ turnover as an emergent property.

\section{Introduction}

Over the last two decades, the development of carbon (C) saturation theory has fundamentally changed our understanding of $\mathrm{C}$ storage in soils, and new biogeochemical models have been developed to include $\mathrm{C}$ saturation dynamics (Hassink and Whitmore, 1997; Kemanian et al., 2005; Stewart et al., 2007; Kemanian et al., 2011). In biogeochemical models that couple $\mathrm{C}$ and nitrogen $(\mathrm{N})$ cycles, $\mathrm{C}$ fluxes drive $\mathrm{N}$ mineralization (reviewed by Manzoni and Porporato, 2009). Thus, altering the structure of a $\mathrm{C}$ model to accommodate saturation dynamics is likely to affect the coupled $\mathrm{N}$ cycle, yet few attempts have been made to understand how $\mathrm{C}$ saturation affects $\mathrm{N}$ cycling (e.g., Castellano et al., 2012). In particular, and to our knowledge, no study has addressed how the $\mathrm{C}$ saturation models proposed in the literature affect simulated $\mathrm{N}$ mineralization dynamics. 
Carbon saturation theory suggests that soils have a limited capacity to stabilize organic $\mathrm{C}$ and that this capacity may be regulated by intrinsic soil properties such as clay concentration and mineralogy (Hassink, 1997; Six et al., 2002). Clay mineral surfaces stabilize and protect organic $\mathrm{C}$ through mineral organic complexes, leading to reduced $\mathrm{C}$ decomposition rates (Baldock and Skjemstad, 2000). As mineral surfaces in a soil become saturated with $\mathrm{C}, \mathrm{C}$ decomposition rates increase, and the rate of soil organic $\mathrm{C}$ storage per unit of $\mathrm{C}$ input declines. This phenomenon results in an asymptotic response of soil organic C stocks to increasing $\mathrm{C}$ inputs (Stewart et al., 2007; Gulde et al., 2008; Heitkamp et al., 2012). Six et al. (2002) proposed a conceptual model of C protection based on measurable pools of organic $\mathrm{C}$, including siltand clay-associated $\mathrm{C}$ pools and particulate organic matter $\mathrm{C}$ pools. Several studies have indicated that the silt- and clayassociated $\mathrm{C}$ pools exhibit a saturating $\mathrm{C}$ storage response to increasing $\mathrm{C}$ inputs, while particulate organic matter increases linearly with C inputs (Gulde et al., 2008; Stewart et al., 2008; Stewart et al., 2012). Given these findings, a new generation of ecosystem models that can simulate physicochemical stabilization of soil organic matter by mineral surfaces, among other processes, is needed to incorporate recent advances in our understanding of $\mathrm{C}$ cycling (Schmidt et al., 2011).

Despite the strong evidence for $\mathrm{C}$ saturation, the majority of ecosystem-scale biogeochemical models that couple $\mathrm{C}$ and $\mathrm{N}$ cycles use linear $\mathrm{C}$ models with no saturation (reviewed by Manzoni and Porporato, 2009). Rothamsted C (Jenkinson, 1990) and Century (Parton et al., 1987) are two widely used non-saturating $\mathrm{C}$ models. In these models, $\mathrm{C}$ decomposition occurs with first-order kinetics, and steady-state $\mathrm{C}$ levels will increase linearly as $\mathrm{C}$ inputs increase. In $\mathrm{C}$ saturation models, however, steady-state $\mathrm{C}$ levels will approach an asymptotic limit as $\mathrm{C}$ inputs increase. Both non-saturation and saturation $\mathrm{C}$ models couple $\mathrm{N}$ mineralization and immobilization $\left(\mathrm{N}_{\mathrm{m}-\mathrm{imm}}\right)$ to $\mathrm{C}$ decomposition $\left(\mathrm{C}_{\mathrm{dec}}\right)$ through the $\mathrm{C}: \mathrm{N}$ ratio $(r)$ of any given pair of decomposing $\left(r_{\mathrm{dec}}\right)$ and receiving $\left(r_{\text {rec }}\right)$ pools and the $\mathrm{C}$ transfer efficiency $\left(\varepsilon, \mathrm{g} \mathrm{C} \mathrm{g}^{-1} \mathrm{C}\right)$ between pools (i.e., the proportion of decomposed $\mathrm{C}$ that is transferred to a receiving pool as organic $\mathrm{C}$ as opposed to being respired as $\mathrm{CO}_{2}$, which is sometimes termed microbial growth efficiency). This coupling is represented as

$N_{\mathrm{m}-\mathrm{imm}}=C_{\mathrm{dec}}\left(\frac{1}{r_{\mathrm{dec}}}-\frac{\varepsilon}{r_{\mathrm{rec}}}\right)$.

The coupling of $\mathrm{C}$ and $\mathrm{N}$ described by Eq. (1) expresses a relationship between $\mathrm{C}$ decomposition, $\mathrm{C}$ respiration, and $\mathrm{N}$ mineralization that will be affected by the structure of a $\mathrm{C}$ saturation model. For instance, one way to implement $\mathrm{C}$ saturation dynamics is by regulating $\varepsilon$ as a function of the $\mathrm{C}$ saturation ratio (the ratio of the actual $\mathrm{C}$ to that of a putative maximum $\mathrm{C}$ level of the saturating pool, $\mathrm{C}_{\mathrm{S}} / \mathrm{C}_{\mathrm{X}}$ ) (Stewart et al., 2007; Kemanian et al., 2011) (Fig. 1a). Alternatively, the transfer rate $\left(k, \mathrm{~T}^{-1}\right)$ to the saturating pool can be regulated

\section{A. Saturation ratio regulates $\varepsilon$}

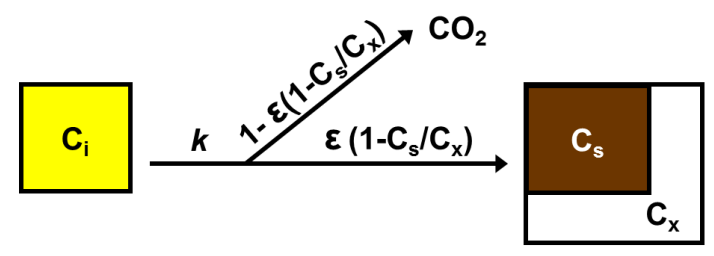

B. Saturation ratio regulates $k$

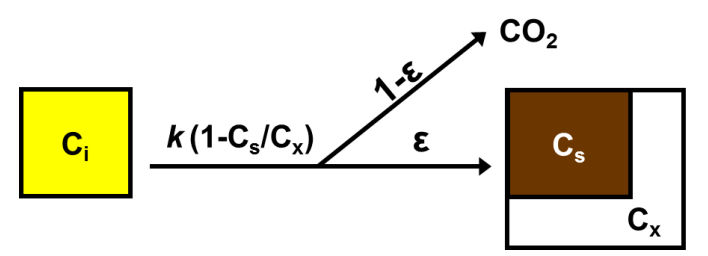

Figure 1. Conceptual models illustrating two different methods of implementing $\mathrm{C}$ saturation dynamics. In both models, the $\mathrm{C}$ saturation ratio of the saturating pool is defined by the ratio of the current pool size $\left(C_{S}\right)$ to a theoretical maximum pool size $\left(C_{X}\right)$, or $C_{S} / C_{X}$. In model $\mathrm{A}$, the $\mathrm{C}$ saturation ratio regulates the $\mathrm{C}$ transfer efficiency $(\varepsilon)$ between the donor pool $\left(\mathrm{C}_{\mathrm{i}}\right)$ and $\mathrm{C}_{\mathrm{S}}$. As the $\mathrm{C}$ saturation ratio increases, less of the $\mathrm{C}$ decomposed from $\mathrm{C}_{\mathrm{i}}$ is transferred to $\mathrm{C}_{\mathrm{S}}$, and more is respired as $\mathrm{CO}_{2}$. In model $\mathrm{B}$, the $\mathrm{C}$ saturation ratio regulates the decomposition rate $(k)$ of $\mathrm{C}_{\mathrm{i}}$, such that the rate decreases as the $\mathrm{C}$ saturation ratio increases. The $\mathrm{C}$ transfer efficiency is not affected by the $\mathrm{C}$ saturation ratio in model $\mathrm{B}$.

as a function of the $\mathrm{C}$ saturation ratio (Hassink and Whitmore, 1997) (Fig. 1b). In both cases, when the saturation ratio increases, $\varepsilon$ and $k$ effectively decrease, because they are regulated multiplicatively by the function $\left(1-\mathrm{C}_{\mathrm{S}} / \mathrm{C}_{\mathrm{x}}\right)($ Fig. 1$)$. These two methods of implementing $\mathrm{C}$ saturation dynamics create explicit couplings between $\mathrm{C}$ saturation and $\mathrm{N}$ mineralization dynamics in different ways, the implications of which have not been explored.

The $\mathrm{N}$ mineralization in Eq. (1) applies to any transfer of $\mathrm{C}$ and $\mathrm{N}$ between pools. The extent to which net $\mathrm{N}$ mineralization occurs as opposed to net $\mathrm{N}$ immobilization depends on the magnitude of $\varepsilon$ and the difference between $r_{\mathrm{dec}}$ and $r_{\mathrm{rec}}$. The $r$ of decomposing plant residue can vary widely across residue types. The critical $r\left(r_{\mathrm{cr}}\right)$ below which decomposing residue will cause positive net $\mathrm{N}$ mineralization can be solved using Eq. (1) when $\mathrm{N}_{\mathrm{m}-\mathrm{imm}}=0$, as shown in Eq. (2).

$r_{\mathrm{cr}}=\frac{r_{\mathrm{rec}}}{\varepsilon}$

This equation shows that a decrease in $\varepsilon$ will increase $r_{\mathrm{cr}}$. For example, if the receiving pool is saturated, the $r_{\mathrm{cr}}$ of decomposing substrates increases. The biological meaning of a decreasing $\varepsilon$ is that a smaller fraction of the products of microbial decomposition stabilize in organo-mineral associations and thus remain available for further microbial decomposition. The $r_{\mathrm{cr}}$ in Eq. (2) is for a single transfer and not for the 
sum of all transfers in a whole soil. A single transfer may immobilize $\mathrm{N}$ while a simultaneous transfer among other pools in the soil may result in net $\mathrm{N}$ mineralization at the whole soil level.

Although the coupling of $\mathrm{C}$ and $\mathrm{N}$ cycles in soils is largely mediated by microbial biomass, the microbial pool has been given little consideration in saturation models. In only one case is the microbial pool explicitly represented in the model structure (Hassink and Whitmore, 1997). This is in contrast to the body of contemporary $\mathrm{C}$ models in the whole, where $60 \%$ of the models include one or more microbial pools (Manzoni and Porporato, 2009). In other C saturation models, the microbial pool is either not included (Stewart et al., 2007) or is implicitly included when parameterizing $\varepsilon$ (Kemanian et al., 2011). In the latter model, $\varepsilon$ lumps in one step what is a cascade of $\mathrm{C}$ transfers among pools mediated by microbial turnover. While this approach may produce reasonable results for net $\mathrm{C}$ exchange in monthly or yearly time frames, when these $\varepsilon$ are used for short time steps, they may obscure the $\mathrm{N}$ cycling during microbial turnover.

A feature that implicitly links non-saturation and saturation $\mathrm{C}$ models is the role of soil clay concentration $\left(f_{\text {clay }}\right)$ in mediating $\varepsilon$ and hence $\mathrm{N}$ mineralization. In $\mathrm{C}$ saturation models, $f_{\text {clay }}$ is used to calculate the maximum size of the saturating pool (Hassink and Whitmore, 1997; Kemanian et al., 2011), thus the $\mathrm{C}$ saturation ratio is a function of $f_{\text {clay. }}$. Models that use the $\mathrm{C}$ saturation ratio to regulate $\varepsilon$ thus connect $f_{\text {clay }}$ to $\varepsilon$. Non-saturating $\mathrm{C}$ cycling models have long used $f_{\text {clay }}$ to regulate $\varepsilon$ directly (Parton et al., 1987; Jenkinson, 1990; Verberne et al., 1990) in a way that leads to lower $\mathrm{N}$ mineralization rates and a lower $r_{\mathrm{cr}}$ in clay-rich soils. This method originated from observations that soils with high $f_{\text {clay }}$ stabilize a greater proportion of $\mathrm{C}$ inputs. For example, Jenkinson (1990) and Parton et al. (1987) used relationships derived from Sørensen (1975) and Sørensen (1981). However, Hassink (1996) found that the C saturation ratio of a soil was a better predictor of $\mathrm{C}$ retention than $f_{\text {clay }}$, suggesting that $\mathrm{C}$ saturation may be a more fundamental mechanism to integrate the effect of soil texture in a coupled $\mathrm{C}$ and $\mathrm{N}$ model. Despite the commonalities in how $f_{\text {clay }}$ controls $\mathrm{N}$ mineralization in both saturating and non-saturating $\mathrm{C}$ models, the behavior of $\mathrm{N}$ mineralization in these two types of $\mathrm{C}$ models has never been formally compared in the literature.

In summary, while $\mathrm{N}$ dynamics are mathematically linked to $\mathrm{C}$ cycling in models with coupled elemental cycles, the implications of $\mathrm{C}$ saturation model structure for simulated $\mathrm{N}$ mineralization dynamics have not been addressed, nor have $\mathrm{N}$ mineralization dynamics in a $\mathrm{C}$ saturation model been compared with those of non-saturation models. To advance the understanding of these areas we propose a set of hypotheses about how the structure and parameterization of different $\mathrm{C}$ models will affect the dynamics of a coupled $\mathrm{N}$ mineralization model. First, the method used to implement $\mathrm{C}$ saturation in a model, either through regulation of transfer efficiency $(\varepsilon)$ or transfer rate $(k)$, will affect $\mathrm{N}$ mineralization dynam- ics. Second, whether or not $\mathrm{C}$ saturation models include an explicit microbial pool through which $\mathrm{C}$ and $\mathrm{N}$ must pass will affect $\mathrm{N}$ mineralization dynamics. Finally, using $\varepsilon$ to implement $\mathrm{C}$ saturation in a model results in soil texture controls on $\mathrm{N}$ mineralization that are similar to those currently included in widely used non-saturating $\mathrm{C}$ and $\mathrm{N}$ models. To test these hypotheses, we compared three different $\mathrm{C}$ saturation models and one non-saturation model (Fig. 2). These model structures were taken from the literature or developed for this investigation. Models varied in whether $\mathrm{C}$ saturation regulated either $\varepsilon$ or $k$ and whether a microbial pool was included in the saturation model. We coupled $\mathrm{N}$ to $\mathrm{C}$ cycling to obtain $\mathrm{N}$ mineralization and illustrate how the $\mathrm{C}$ model structure affects the $r_{\mathrm{cr}}$ and the temporal dynamics of a simulated inorganic $\mathrm{N}$ pool during plant residue decomposition.

\section{Methods}

\subsection{Structure of the carbon models}

We focused on three $\mathrm{C}$ saturation models with increasing complexity and one non-saturation $\mathrm{C}$ model (Fig. 2). The first and simplest model in our study is a single-pool saturation model, adapted from the models proposed by Kemanian et al. $(2005,2011)$ and Stewart et al. (2007). The second model expands the single-pool saturation model by adding a microbial pool $\left(\mathrm{C}_{\mathrm{m}}\right)$. We termed this model the microbial saturation model to reflect the explicit inclusion of a microbial pool through which $\mathrm{C}$ and $\mathrm{N}$ must pass. The third model is the abiotic saturation model, whose structure was proposed by Hassink and Whitmore (1997). This model includes a microbial pool $\left(\mathrm{C}_{\mathrm{m}}\right)$, a labile unprotected pool $\left(\mathrm{C}_{\mathrm{un}}\right)$, and a saturating pool of protected $\mathrm{C}\left(\mathrm{C}_{\mathrm{s}}\right)$. We called this the abiotic saturation model because the saturating pool is directly linked to the labile pool and any transfers are abiotic sorption and desorption. We compared these three $\mathrm{C}$ saturation models to the Rothamsted C (RothC) model (Jenkinson, 1990), which is based on first-order kinetics and which results in a linear relationship between $\mathrm{C}$ input and steady-state $\mathrm{C}$ level.

Because the main purpose of this study is to compare how the structure of $\mathrm{C}$ models affects $\mathrm{N}$ mineralization, rather than $\mathrm{C}$ storage, we forced the turnover rate parameters so that each model would return similar steady-state $\mathrm{C}$ stocks at a given level of fresh $\mathrm{C}$ inputs. We used turnover rates from RothC as defaults and the resulting steady state soil $\mathrm{C}$ as a reference for other models. A detailed description of each model is provided in the following sections. For reference, model structures are diagrammed in Fig. 2, parameters are specified in Table 1, and the differential equations for each pool are in Table 2.

\subsubsection{Single-pool saturation model}

In the single-pool saturation model, decomposed $\mathrm{C}$ from the pool of residue inputs $\left(C_{r}\right)$ is transferred directly to $C_{S}$. The 
A. Single-pool Saturation

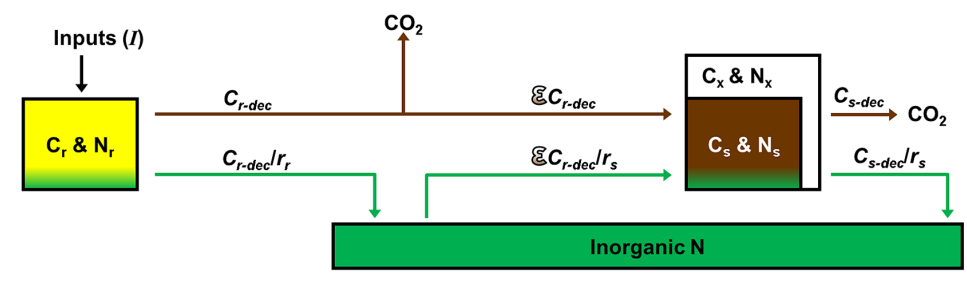

B. Microbial Saturation

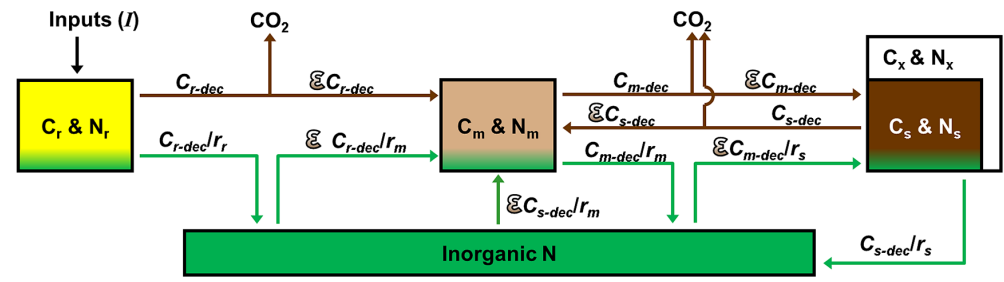

\section{Abiotic Saturation}

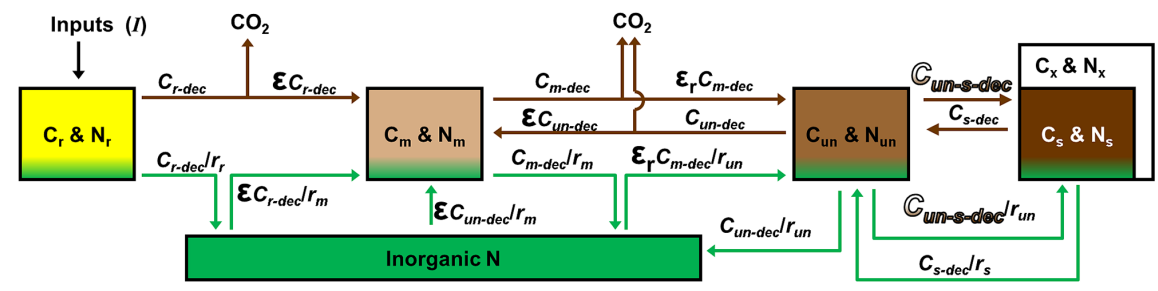

D. RothC

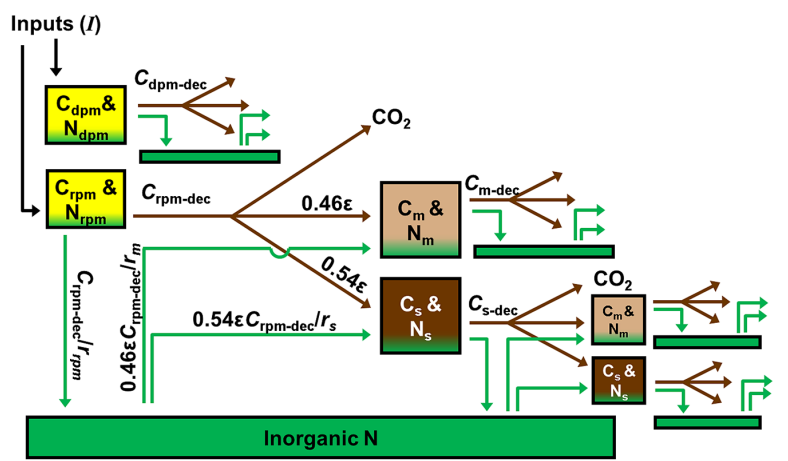

Figure 2. Diagrams of the pools and fluxes in the four models used in this study. Carbon and $\mathrm{N}$ pools are indicated together in boxes. Carbon fluxes are indicated by brown arrows and $\mathrm{N}$ fluxes by green arrows. Pools are abbreviated as follows: $\mathrm{C}_{\mathrm{r}}, \mathrm{C}_{\mathrm{dpm}}, \mathrm{C}_{\mathrm{rpm}}$ and $\mathrm{N}_{\mathrm{r}}, \mathrm{N}_{\mathrm{dpm}}$, $\mathrm{N}_{\mathrm{rpm}}$ are plant residues; $\mathrm{C}_{\mathrm{m}}$ and $\mathrm{N}_{\mathrm{m}}$ are microbial biomasses; $\mathrm{C}_{\mathrm{un}}$ and $\mathrm{N}_{\mathrm{un}}$ are unprotected soil organic matter; $\mathrm{C}_{\mathrm{s}}$ and $\mathrm{N}_{\mathrm{s}}$ are protected or stabilized soil organic matter; $\mathrm{C}_{\mathrm{X}}$ and $\mathrm{N}_{\mathrm{X}}$ are the maximum or saturating capacity for $\mathrm{C}$ and $\mathrm{N}$ storage. The inorganic $\mathrm{N}$ pool is represented by a green box. Carbon decomposition from each pool and the pool stoichiometry $\left(\mathrm{C}: \mathrm{N}\right.$ ratio) are represented by the symbols $\mathrm{C}_{j-\mathrm{dec}}$ and $r_{j}$, respectively, where $j$ specifies the pool. Pools decompose with first-order kinetics based on rates listed in Table 1 . The symbol $\varepsilon$ is the $\mathrm{C}$ transfer efficiency to the receiving pool, the value of which is specified by Table 1 for each model. Symbols illustrated with a brown gradient fill pattern are regulated by the $\mathrm{C}$ saturation ratio $\left(\mathrm{C}_{\mathrm{S}} / \mathrm{C}_{\mathrm{X}}\right)$.

$\varepsilon$ from $\mathrm{C}_{\mathrm{r}}$ to $\mathrm{C}_{\mathrm{s}}$ is regulated by an efficiency factor $\left(\varepsilon_{\mathrm{X}}\right)$ and the saturation ratio $\left(\mathrm{C}_{\mathrm{S}} / \mathrm{C}_{\mathrm{X}}\right)$. We calculate $\mathrm{C}_{\mathrm{X}}$ as a function of $f_{\text {clay }}$ using the formula developed by Hassink and Whitmore (1997). In this model, $\varepsilon_{\mathrm{x}}$ represents a humification coefficient (sensu Hénin and Dupuis, 1945), or the slope that would be obtained by regressing $\mathrm{dC}_{\mathrm{s}} / \mathrm{d} t$ against $\mathrm{C}$ in- puts. This coefficient is an effective efficiency that lumps the $\mathrm{C}$ use efficiency of the microbes feeding on residues and on microbial biomass (predation), detritus and exudates. We used $\varepsilon_{\mathrm{x}}=0.18 \mathrm{~g} \mathrm{C} \mathrm{g}^{-1} \mathrm{C}$. This value is in the upper range reported by Huggins et al. (1998), and would correspond to three cycles of microbial feeding with a $\mathrm{C}$ use efficiency of 
Table 1. The parameter values used in each model.

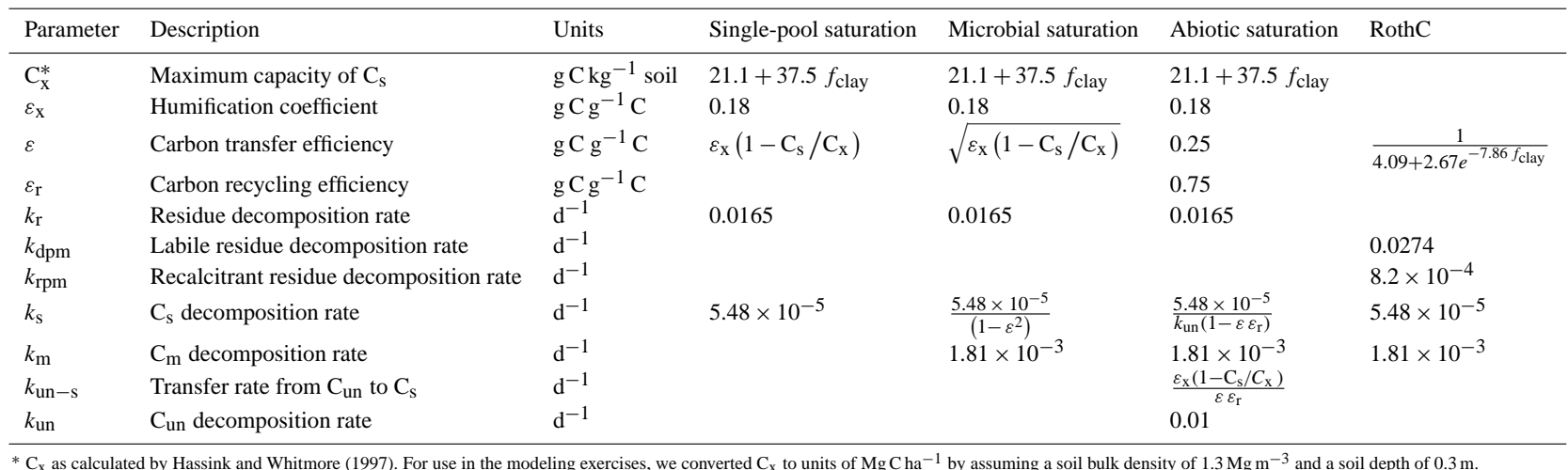

${ }^{*} \mathrm{C}_{\mathrm{X}}$ as calculated by Hassink and Whitmore (1997). For use in the modeling exercises, we converted $\mathrm{C}_{\mathrm{X}}$ to units of $\mathrm{Mg} \mathrm{Cha}^{-1}$ by assuming a soil bulk density of $1.3 \mathrm{Mg} \mathrm{m}{ }^{-3}$ and a soil depth of $0.3 \mathrm{~m}$.

Table 2. Differential equations for carbon pools in each model.

\begin{tabular}{ll}
\hline Single-pool saturation model \\
\hline $\mathrm{dC}_{\mathrm{r}} / \mathrm{d} t=I^{*}-k_{\mathrm{r}} \mathrm{C}_{\mathrm{r}}$ \\
$\mathrm{d} \mathrm{C}_{\mathrm{s}} / \mathrm{d} t=\varepsilon k_{\mathrm{r}} \mathrm{C}_{\mathrm{r}}-k_{\mathrm{s}} \mathrm{C}_{\mathrm{s}}$ \\
\hline Microbial saturation model \\
\hline $\mathrm{d}_{\mathrm{r}} / \mathrm{d} t=I-k_{\mathrm{r}} \mathrm{C}_{\mathrm{r}}$ \\
$\mathrm{d} \mathrm{C}_{\mathrm{m}} / \mathrm{d} t=\varepsilon k_{\mathrm{r}} \mathrm{C}_{\mathrm{r}}+\varepsilon k_{\mathrm{s}} \mathrm{C}_{\mathrm{s}}-k_{\mathrm{m}} \mathrm{C}_{\mathrm{m}}$ \\
$\mathrm{d} \mathrm{C}_{\mathrm{s}} / \mathrm{d} t=\varepsilon k_{\mathrm{m}} \mathrm{C}_{\mathrm{m}}-k_{\mathrm{s}} \mathrm{C}_{\mathrm{s}}$ \\
\hline Abiotic saturation model \\
\hline $\mathrm{dC}_{\mathrm{r}} / \mathrm{d} t=I-k_{\mathrm{r}} \mathrm{C}_{\mathrm{r}}$
\end{tabular}

* $I=$ plant residue $\mathrm{C}$ inputs.

$0.56 \mathrm{~g} \mathrm{C} \mathrm{g}^{-1} \mathrm{C}$ (i.e., $0.56^{3}$ ). This $\mathrm{C}$ use efficiency agrees well with a representative upper value in soils reported in Fig. 6 of Manzoni et al. (2012). Both $\mathrm{C}_{\mathrm{r}}$ and $\mathrm{C}_{\mathrm{s}}$ decay with first-order kinetics according to the rate constants in Table 1. Decomposed $\mathrm{C}$ that is not transferred to $\mathrm{C}_{\mathrm{s}}$ is respired as $\mathrm{CO}_{2}$. The turnover rate of soil C $\left(k_{\mathrm{s}}\right)$ in this model is taken from RothC. The residue $\mathrm{C}$ pool turnover rate $\left(k_{\mathrm{r}}\right)$ in all three saturation models is taken as the weighted average of the turnover rates for decomposable $\left(k_{\mathrm{dpm}}\right)$ and resistant $\left(k_{\mathrm{rpm}}\right)$ plant material input pools in RothC (i.e., $0.59 k_{\mathrm{dpm}}+0.41 k_{\mathrm{rpm}}$ ).

\subsubsection{Microbial saturation model}

In the microbial saturation model, $\mathrm{C}$ decomposed from $\mathrm{C}_{\mathrm{r}}$ and $C_{s}$ is transferred to $C_{m}$ while $C$ decomposed from $C_{m}$ is transferred to $\mathrm{C}_{\mathrm{s}}$. The $\varepsilon$ from decomposing pools to receiving pools is calculated as the square root of the $\varepsilon$ used in the single-pool saturation model. Thus, $\mathrm{C}$ that is stepping from $C_{r}$ to $C_{m}$ and from $C_{m}$ to $C_{s}$ is retained with an overall efficiency similar to the single-pool model. Decomposed $\mathrm{C}$ that is not transferred to a receiving pool is respired as $\mathrm{CO}_{2}$. The three pools $\mathrm{C}_{\mathrm{r}}, \mathrm{C}_{\mathrm{m}}$, and $\mathrm{C}_{\mathrm{s}}$ decay with first-order kinetics. The turnover rate of the microbial pool $\left(k_{\mathrm{m}}\right)$ in this model is taken from RothC while $k_{\mathrm{S}}$ is derived to maintain a steady state $\mathrm{C}_{\mathrm{s}}$ level that is equivalent to the single-pool saturation model. The derivation for $k_{\mathrm{s}}$ is provided in Appendix A. 


\subsubsection{Abiotic saturation model}

The abiotic saturation model is adapted from the structure proposed by Hassink and Whitmore (1997). Decomposed C from $\mathrm{C}_{\mathrm{r}}$ and $\mathrm{C}_{\mathrm{un}}$ is transferred to $\mathrm{C}_{\mathrm{m}}$ with a fixed $\varepsilon$ representing microbial $\mathrm{C}$ use efficiency. Carbon in $\mathrm{C}_{\mathrm{un}}$ is also transferred to $\mathrm{C}_{\mathrm{s}}$, a protected pool, simulating the abiotic sorption of organic $\mathrm{C}$ to mineral surfaces. The transfer rate from $\mathrm{C}_{\mathrm{un}}$ to $\mathrm{C}_{\mathrm{s}}\left(k_{\mathrm{un}-\mathrm{s}}\right)$ is controlled by a maximum rate that is regulated by the size of $\mathrm{C}_{\mathrm{s}}$ relative to its maximum capacity $\left(C_{\mathrm{x}}\right)$, with the latter being calculated as a function of $f_{\text {clay }}$ using the original linear regression developed by Hassink and Whitmore. Transfer of $\mathrm{C}$ from $\mathrm{C}_{\mathrm{s}}$ to $\mathrm{C}_{\mathrm{un}}$, representing the desorption of organic $\mathrm{C}$ from the mineral phase, occurs at the rate $k_{\mathrm{s}}$. Because the sorption-desorption process is abiotic, the $\varepsilon$ between $\mathrm{C}_{\mathrm{un}}$ and $\mathrm{C}_{\mathrm{s}}$ is 1 (no $\mathrm{CO}_{2}$ is respired in the transfer). The turnover rates $k_{\mathrm{r}}$ and $k_{\mathrm{m}}$ are consistent with the other saturation models. We set the default value for the decay rate $k_{\text {un }}$ at $0.01 \mathrm{~d}^{-1}$ while the decay rates $k_{\text {un-s }}$ and $k_{\mathrm{s}}$ were derived such that steady state $C_{\mathrm{s}}$ level would be equivalent to the single-pool saturation model (see Appendix A for the derivation).

\subsubsection{Rothamsted C model}

In the RothC model (Jenkinson, 1990), C pools include decomposable $\left(\mathrm{C}_{\mathrm{dpm}}\right)$ and resistant $\left(\mathrm{C}_{\mathrm{rpm}}\right)$ fractions of plant material inputs, and microbial $\left(\mathrm{C}_{\mathrm{m}}\right)$ and stabilized $\left(\mathrm{C}_{\mathrm{s}}\right)$ pools of soil C. Each pool decays with its own first-order rate constant. Decomposed C from each pool is transferred to the receiving pools with an efficiency $(\varepsilon)$ that is determined by $f_{\text {clay }}$. This efficiency varies from a low of 0.15 at 0.01 clay concentration to a plateau of approximately 0.24 at 0.45 clay concentration. The fraction of decomposed $\mathrm{C}$ that is not transferred to a receiving pool $(1-\varepsilon)$ is respired as $\mathrm{CO}_{2}$. Of the total $\mathrm{C}$ decomposed from all pools and not lost as $\mathrm{CO}_{2}$, $54 \%$ is transferred to $C_{s}$ and $46 \%$ is transferred to $C_{m}$.

\subsection{Modeling N mineralization}

We coupled a simple $\mathrm{N}$ mineralization-immobilization model to each of the four $\mathrm{C}$ models using the convention described in Eq. (1). The coupling of $\mathrm{C}$ and $\mathrm{N}$ for each model structure is diagrammed in Fig. 2. In this $\mathrm{N}$ mineralization model, $\mathrm{N}$ decomposes from the donor pool in proportion to $\mathrm{C}$ decomposition based on the $r_{\mathrm{dec}}$. A portion of the decomposed $\mathrm{C}$ is transferred to a receiving pool based on $\varepsilon$, while the remaining $\mathrm{C}$ is respired as $\mathrm{CO}_{2}$. Decomposed organic $\mathrm{N}$ is transferred to the receiving pool in proportion to the $\mathrm{C}$ received by the pool based on the $r_{\text {rec }}$. Nitrogen mineralization (or immobilization) is calculated as the difference between the $\mathrm{N}$ decomposed and the $\mathrm{N}$ assimilated by the receiving pool. Nitrogen mineralized as a result of $\mathrm{C}$ decomposition is added to an inorganic $\mathrm{N}\left(\mathrm{N}_{\mathrm{i}}\right)$ pool. When $\mathrm{N}_{\mathrm{m}-\mathrm{imm}}$ is negative, immobilization occurs, and $\mathrm{N}$ is removed from the $\mathrm{N}_{\mathrm{i}}$ pool. If the pool size of $\mathrm{N}_{\mathrm{i}}$ is insufficient to meet the immobilization demand, $\mathrm{C}$ decomposition is limited by $\mathrm{N}$ availability, as we assume that $\varepsilon$ will not change. Under such circumstances, we calculate the reduced $\mathrm{C}$ decomposition by rearranging Eq. (1) and assuming that $\mathrm{N}_{\mathrm{i}}+\mathrm{N}_{\mathrm{m}-\mathrm{imm}}=0$ :

$C_{\mathrm{dec}}=\frac{\mathrm{N}_{\mathrm{i}}}{\frac{\varepsilon}{r_{\mathrm{rec}}}-\frac{1}{r_{\mathrm{dec}}}}$

We use a fixed $r$ of 10 for the microbial and soil organic matter pools, while the $r$ of the input residues was a variable parameter input to the model.

To maintain the simplicity of our $\mathrm{N}$ model, we do not include $\mathrm{N}$ transformations such as nitrification or $\mathrm{N}$ losses such as leaching and plant uptake. Thus, in time series modeling exercises, the $\mathrm{N}_{\mathrm{i}}$ pool represents the cumulative sum of net $\mathrm{N}$ mineralization and immobilization. Due to the simplification of our $\mathrm{N}$ model, we do not include $\mathrm{N}$ cycling feedbacks on $\mathrm{C}$ cycling, which are known to exist in nature and are sometimes included in more sophisticated models (e.g., Schimel and Weintraub, 2003; Eliasson and Ågren, 2011)

\subsection{Modeling exercises}

To study and illustrate the differences in $\mathrm{C}$ and $\mathrm{N}$ cycling among the four models and the implications of the $\mathrm{C}$ model structure for $\mathrm{N}$ mineralization, we did the following: (i) derived the analytical solutions to the steady-state size of each $\mathrm{C}$ pool as a function of $\mathrm{C}$ input level for all models; (ii) calculated the $r_{\mathrm{cr}}$ for a range of $f_{\text {clay }}$ and saturation ratios; and (iii) simulated the temporal dynamics of $\mathrm{N}$ mineralization at a daily time step following a one-time residue addition.

In the daily time step residue addition simulation, a $5 \mathrm{MgC} \mathrm{ha}^{-1}$ mass of plant residues with a $r$ of 60 added to the soil on day 1 was allowed to decompose for 365 days. Nitrogen mineralization and/or immobilization resulting from residue and soil organic matter decomposition was added to or removed from the $\mathrm{N}_{\mathrm{i}}$ pool. The simulation was conducted for 0.05 clay concentration and 0.25 clay concentration soils. Soil organic $\mathrm{C}$ pool sizes in each model were initialized to steady-state levels for an annual plant residue addition level of $5 \mathrm{MgCha}^{-1}$ (equations in Table 3). The $\mathrm{N}_{\mathrm{i}}$ pool was initialized to a size of $0.05 \mathrm{Mg} \mathrm{N} \mathrm{ha}^{-1}$ to prevent $\mathrm{N}$ limitation of decomposition during the modeling exercise. Simulations were conducted in Microsoft Excel using the Visual Basic for Applications programming language.

\section{Results}

\subsection{Characteristics and behavior of the $\mathrm{C}$ models}

As expected, steady-state levels of $\mathrm{C}$ pools in each model responded to increasing $\mathrm{C}$ inputs in either a saturating or linear manner, based on the parameterization of each model structure (Table 3 and Fig. 3 ). The $\mathrm{C}_{\mathrm{s}}$ pool saturates in all three 
Table 3. Analytical solutions to the steady-state level of the SOC pools in each model. Carbon input rate $(I)$ and turnover rates $k_{\mathrm{S}}$, $k_{\mathrm{m}}$, and $k_{\text {un }}$ must have same time units.

\begin{tabular}{l}
\hline \multicolumn{3}{l}{ All saturation models } \\
\hline $\mathrm{C}_{\mathrm{s}}=\frac{\varepsilon_{\mathrm{x}} I}{k_{\mathrm{s}}^{*}+\varepsilon_{\mathrm{x}} \mathrm{C}_{\mathrm{r}} / \mathrm{C}_{\mathrm{x}}}$ \\
\hline Microbial saturation model \\
\hline $\mathrm{C}_{\mathrm{m}}=\frac{\sqrt{\varepsilon_{\mathrm{x}}\left(1-\mathrm{C}_{\mathrm{s}} / \mathrm{C}_{\mathrm{x}}\right)} I}{k_{\mathrm{m}}\left(1-\varepsilon_{\mathrm{x}}\left(1-\mathrm{C}_{\mathrm{s}} / \mathrm{C}_{\mathrm{x}}\right)\right)}$ \\
\hline Abiotic saturation model \\
\hline $\mathrm{C}_{\mathrm{m}}=\frac{\varepsilon I}{k_{\mathrm{m}}\left(1-\varepsilon \varepsilon_{\mathrm{r}}\right)}$ \\
$\mathrm{C}_{\mathrm{un}}=\frac{\varepsilon \varepsilon_{\mathrm{r}} I}{k_{\mathrm{un}}\left(1-\varepsilon \varepsilon_{\mathrm{r}}\right)}$ \\
\hline RothC \\
\hline$C_{\mathrm{s}}=\frac{0.54 \varepsilon I}{k_{\mathrm{s}}(1-\varepsilon)}$ \\
$C_{\mathrm{m}}=\frac{0.46 \varepsilon I}{k_{\mathrm{m}}(1-\varepsilon)}$ \\
* The $k_{\mathrm{s}}$ parameter value from the single-pool \\
saturation model.
\end{tabular}

saturation models and $\mathrm{C}_{\mathrm{m}}$ saturates in the microbial saturation model. In the single-pool saturation and microbial saturation models, this results because the $\mathrm{C}$ transfer efficiency $(\varepsilon)$ to $\mathrm{C}_{\mathrm{s}}$ and $\mathrm{C}_{\mathrm{m}}$ is regulated by the $\mathrm{C}$ saturation ratio. As $\mathrm{C}$ saturation increases, more $\mathrm{C}$ is respired as $\mathrm{CO}_{2}$ in the transfer and less is retained by the receiving pool. The $\mathrm{C}_{\mathrm{s}}$ pool saturates in the abiotic saturation model because $k_{\mathrm{un}-\mathrm{s}}$ is regulated by the $\mathrm{C}$ saturation ratio. As $\mathrm{C}$ saturation increases, less $\mathrm{C}$ is transferred from $\mathrm{C}_{\mathrm{un}}$ to $\mathrm{C}_{\mathrm{s}}$. In the abiotic saturation model, $\mathrm{C}_{\mathrm{m}}$ and $\mathrm{C}_{\mathrm{un}}$ are non-saturating and respond linearly to increasing $\mathrm{C}$ inputs, as do all the pools in RothC. The linear response is because the $\varepsilon$ to these pools is a fixed value. Increasing $f_{\text {clay }}$ from 0.05 to 0.25 led to increased $\mathrm{C}$ storage in the $\mathrm{C}_{\mathrm{s}}$ pools of all saturation models and RothC, and the $\mathrm{C}_{\mathrm{m}}$ pools of the microbial saturation model and RothC (Fig. 3). In the abiotic saturation model, $\mathrm{C}_{\mathrm{m}}$ and $\mathrm{C}_{\mathrm{un}}$ levels were unaffected by $f_{\text {clay }}$.

When $\mathrm{C}$ input levels and soil clay concentration were low, only small differences in total $\mathrm{C}$ storage were predicted by each model, as calculated by summing the mass of all $\mathrm{C}$ pools (Fig. 3c and d). However, at higher $\mathrm{C}$ input levels and soil clay concentration, large divergences between the saturation models and RothC occurred owing to the asymptotic characteristic of saturation models. Even though the abiotic saturation model contained the non-saturating pools $\mathrm{C}_{\mathrm{un}}$ and $\mathrm{C}_{\mathrm{m}}$, the overall response of total $\mathrm{C}$ storage to increasing $\mathrm{C}$ inputs was similar to that of a pure saturation model. This is because of the relatively small size of the $\mathrm{C}_{\mathrm{un}}$ and $\mathrm{C}_{\mathrm{m}}$ pools compared to $\mathrm{C}_{\mathrm{S}}$ when $\mathrm{C}$ inputs are within the range typical of most ecosystems $\left(<15 \mathrm{MgC} \mathrm{ha}^{-1} \mathrm{y}^{-1}\right)$.
Table 4. The analytical solution to $r_{\mathrm{cr}}$ in each model.

\begin{tabular}{ll}
\hline Single-pool saturation \\
\hline$r_{\mathrm{cr}}=\frac{r_{\mathrm{s}}}{\varepsilon_{\mathrm{x}}\left(1-\mathrm{C}_{\mathrm{s}} / C_{\mathrm{x}}\right)}$ \\
\hline Microbial saturation \\
\hline$r_{\mathrm{cr}}=\frac{r_{\mathrm{m}}}{\sqrt{\varepsilon_{\mathrm{x}}\left(1-\mathrm{C}_{\mathrm{s}} / C_{\mathrm{x}}\right)}}$ \\
\hline Abiotic saturation \\
\hline$r_{\mathrm{cr}}=\frac{r_{\mathrm{m}}}{0.25}$ \\
\hline RothC \\
\hline$r_{\mathrm{cr}}=\left(0.54 r_{\mathrm{s}}+0.46 r_{\mathrm{m}}\right)\left(4.0+2.67 e^{\left.-7.86 f_{\text {clay }}\right)}\right.$ \\
\hline
\end{tabular}

\subsection{Nitrogen mineralization dynamics}

The method used to implement $\mathrm{C}$ saturation in a model, by regulating either transfer efficiency $(\varepsilon)$ or transfer rate $(k)$, affected $\mathrm{N}$ mineralization dynamics. When $\mathrm{C}$ saturation is implemented by regulating $\varepsilon$, as in the single-pool saturation and microbial saturation models, the saturation ratio affects the $r_{\text {cr }}$ of decomposing plant residues (Table 4, Fig. 4a). In these models, $r_{\mathrm{cr}}$ increases as the saturation ratio increases. On the other hand, when $\mathrm{C}$ saturation is implemented by regulating $k$, as in the abiotic saturation model, $r_{\mathrm{cr}}$ is independent of the saturation ratio (Table 4, Fig. 4a).

The explicit inclusion of a microbial pool in the $\mathrm{C}$ saturation models also affected $\mathrm{N}$ mineralization dynamics. When a microbial pool was not explicitly included, as in the singlepool saturation model, $r_{\mathrm{cr}}$ ranged from 55 to nearly 1000 over the saturation ratio gradient (Fig. 4a). In the microbial saturation and abiotic saturation models, where $\mathrm{C}$ and $\mathrm{N}$ flow through a microbial pool, $r_{\mathrm{cr}}$ was lower and had a narrower range over the saturation ratio gradient. In the microbial saturation model, $r_{\mathrm{cr}}$ ranged from 25 to 200 over the saturation ratio gradient while the abiotic saturation model had a fixed $r_{\mathrm{cr}}$ of 40 (Fig. 4a). The inclusion of a microbial pool also affected the temporal dynamics of $\mathrm{N}$ mineralization during simulated residue decomposition. In the microbial saturation and abiotic saturation models, decomposition of plant residue with $r=60$ led to an initial period of net $\mathrm{N}$ immobilization, whereas the single-pool saturation model predicted immediate net $\mathrm{N}$ mineralization (Fig. 5).

Using $\varepsilon$ to implement $C$ saturation in the single-pool saturation and microbial saturation models led to soil texture controls on $\mathrm{N}$ mineralization that were similar to RothC, a widely used non-saturating model. In these three models, $r_{\mathrm{cr}}$ decreased as clay concentration increased (Fig. 4b). The $r_{\mathrm{cr}}$ in RothC decreased from 59 at a clay concentration of 0.05 to 41 at a clay concentration of 0.80 . Across the same clay concentration gradient, $r_{\mathrm{cr}}$ in the single-pool saturation model decreased from 86 to 66 and $r_{\mathrm{cr}}$ in the microbial saturation model decreased from 29 to 26 . 

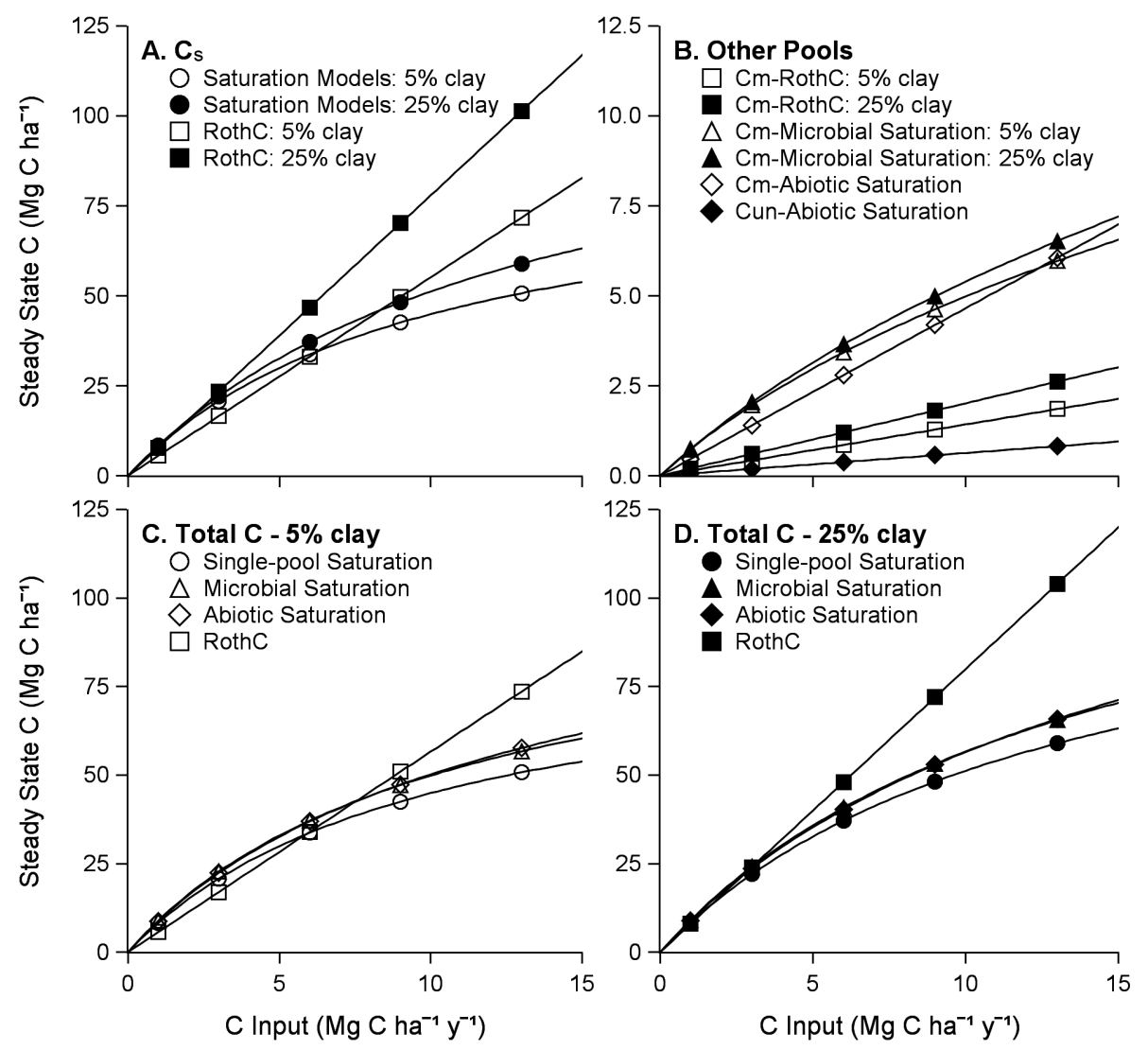

Figure 3. The relationship between $\mathrm{C}$ input level and the steady-state $\mathrm{C}$ level of various pools in each model for soils with contrasting clay concentration. (a) The $\mathrm{C}_{\mathrm{s}}$ pool of each model in soils with 0.05 and 0.25 clay concentration. (b) Other $\mathrm{C}$ pools in each model in soils with 0.05 and 0.25 clay concentration (note: the pools in the abiotic saturation model are not sensitive to clay concentration). (c, d) The total C pool size in soils with 0.05 clay concentration (c) and 0.25 clay concentration (d).
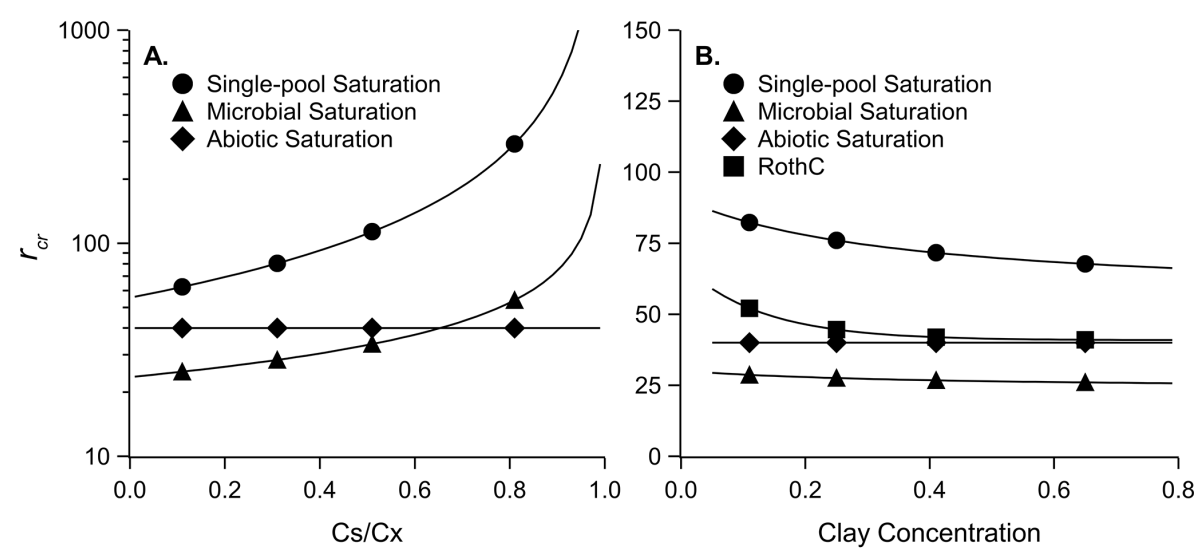

Figure 4. The critical $\mathrm{C}: \mathrm{N}$ ratio $\left(r_{\mathrm{cr}}\right)$ as a function of carbon saturation ratio (a) and clay concentration (b). In (b), the pool size for $\mathrm{C}_{\mathrm{S}}$ was maintained constant at $32 \mathrm{Mg} \mathrm{Cha}^{-1}$; thus, the clay gradient creates a $\mathrm{C}$ saturation gradient. For reference, a pool size of $32 \mathrm{Mg} \mathrm{Cha}{ }^{-1}$ would result from an annual $\mathrm{C}$ input level of $\sim 5 \mathrm{MgCha}^{-1} \mathrm{y}^{-1}$.

\section{Discussion}

A significant result from our work is that, despite similar predictions of $\mathrm{C}$ storage across the saturation models, dynamics of $\mathrm{N}$ mineralization diverged widely due to the structure of each model. We revealed two important considerations for how $\mathrm{C}$ saturation models can be linked to $\mathrm{N}$ mineralization dynamics. First, the influence of $\mathrm{C}$ saturation on $\mathrm{N}$ mineral- 


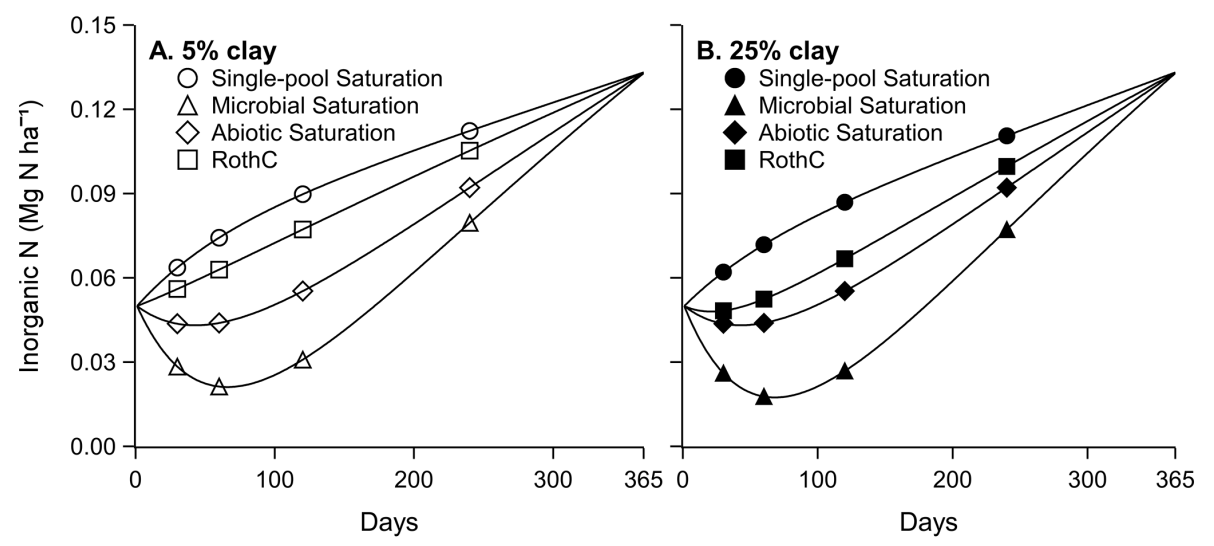

Figure 5. The inorganic $\mathrm{N}$ pool during decomposition of a $5 \mathrm{Mg} \mathrm{Cha}^{-1}$ residue addition with a $r$ of 60 in a soil with 0.05 clay concentration (a) and 0.25 clay concentration (b). Soil $\mathrm{C}$ pool sizes for each model structure were initialized to the steady-state levels that would occur from annual residue additions of $5 \mathrm{Mg} \mathrm{Cha}^{-1}$. Residue and soil $\mathrm{C}$ pools decomposed at the optimum rates listed in Table 1.

ization dynamics depends on whether $\mathrm{C}$ saturation is modeled as a process regulating transfer efficiencies or a process regulating transfer rates. Second, a single-pool C saturation model that may predict long-term $\mathrm{C}$ storage well can misrepresent short-term $\mathrm{N}$ mineralization if $\mathrm{N}$ cycling is simply linked to the long cadence of $\mathrm{C}$ cycling. For example, the single-pool $\mathrm{C}$ saturation model predicted $\mathrm{N}$ mineralization from high $r$ ratio litter inputs $(r>60)$ which normally result in $\mathrm{N}$ immobilization (Manzoni et al., 2008; Sinsabaugh et al., 2013). This mismatch between $\mathrm{C}$ and $\mathrm{N}$ cycling can be greatly improved by simply adding an intermediate pool of microbial biomass through which $\mathrm{C}$ and $\mathrm{N}$ must pass, an addition that does not affect long-term $\mathrm{C}$ cycling. Finally, we demonstrated that soil texture controls on $\mathrm{N}$ mineralization can be similar between saturation and non-saturation models. These findings have important implications about how the structure of $\mathrm{C}$ saturation models affect $\mathrm{N}$ mineralization and offer new hypotheses about the links between $\mathrm{C}$ saturation and $\mathrm{N}$ mineralization processes that should be tested with further research, as described in the following sections.

\subsection{Regulating $\varepsilon$ vs. $k$ to implement $C$ saturation affects $\mathrm{N}$ mineralization dynamics}

The influence of $\mathrm{C}$ saturation on $\mathrm{N}$ mineralization dynamics depends on whether $\mathrm{C}$ saturation is modeled as a process regulating $\varepsilon$ or $k$. In the single-pool and microbial saturation models, the $\mathrm{C}$ saturation ratio is used to regulate $\varepsilon$, coupling $\mathrm{C}$ saturation and $\mathrm{N}$ mineralization processes based on Eq. (1). In the abiotic saturation model, where the saturation ratio does not regulate $\varepsilon$ but rather $k, \mathrm{C}$ saturation does not affect $\mathrm{N}$ mineralization dynamics. These differences in how the models simulate $\mathrm{C}$ saturation present contrasting hypotheses of how $\mathrm{C}$ saturation could affect $\mathrm{N}$ mineralization dynamics.

If $\mathrm{C}$ saturation does affect $\mathrm{N}$ mineralization, there may be important implications for ecosystem management. For example, increasing $\mathrm{C}$ inputs to an ecosystem to promote $\mathrm{C}$ se- questration, or large disposals of manure in the soil, would move the soil closer to $\mathrm{C}$ saturation, causing more $\mathrm{N}$ mineralization from the inputs and potentially increased $\mathrm{N}$ losses. Management practices that redistribute SOC concentrations in a soil profile and mix layers with higher saturation ratios (e.g., top layer in no-till systems) with layers of lower saturation would result in altered $\mathrm{N}$ mineralization patterns from crop residues.

A limited number of studies address these potential implications. Castellano et al. (2012) presented a conceptual model linking $\mathrm{C}$ and $\mathrm{N}$ saturation theories that was supported by evidence that increasing levels of $\mathrm{C}$ saturation reduced the transfer of $\mathrm{NH}_{4}-\mathrm{N}$ to mineral-associated organic matter and increased potential net nitrification. Similarly, McLauchlan (2006) found that net $\mathrm{N}$ mineralization decreased as clay concentration increased in soils aggrading $\mathrm{C}$ following agricultural abandonment. The findings of both of these studies are consistent with the behavior of a $\mathrm{C}$ saturation model where the $\mathrm{C}$ saturation ratio regulates $\varepsilon$. In such a model, increasing $\mathrm{C}$ saturation would reduce $\varepsilon$, resulting in less $\mathrm{N}$ immobilization (as in Castellano et al., 2012) or greater $\mathrm{N}$ mineralization (as in McLauchlan, 2006).

\subsection{Inclusion of a microbial pool in C saturation models affects $\mathrm{N}$ mineralization dynamics}

In order to obtain reasonable predictions of $\mathrm{N}$ mineralization from decomposing plant residues, it was necessary to include an explicit microbial pool in the $\mathrm{C}$ saturation model. In the single-pool saturation model, an explicit microbial pool is not included, rather an effective $\mathrm{C}$ transfer efficiency between $\mathrm{C}_{\mathrm{r}}$ and $\mathrm{C}_{\mathrm{s}}$ lumps approximately three cycles of microbial predation into one step. This approach has been used to predict $\mathrm{C}$ storage accurately over decadal timescales (Kemanian and Stöckle, 2010), and a single-pool model offers the advantages of parsimony (Stewart et al., 2007) and simplicity of calibration requirements (Kemanian and Stöckle, 
2010). However, when coupled to a model of $\mathrm{N}$ mineralization, the single-pool saturation model yielded a $r_{\mathrm{cr}}$ that ranged from 55 to over 555 as the $\mathrm{C}$ saturation ratio rose above 0.9 (Fig. 4a). This range of $r_{\mathrm{cr}}$ is above the range that has been observed across a variety of ecosystem and substrate types, except for woody residue substrates (Manzoni et al., 2008).

The steepness of the rise in $r_{\mathrm{cr}}$ as the $\mathrm{C}$ saturation ratio increases in the single-pool model could be tempered by exponentiating the $\mathrm{C}$ saturation ratio. For example, Kemanian et al. (2011) raised the $\mathrm{C}$ saturation ratio to the sixth power. While this method may maintain $r_{\mathrm{cr}}$ at more reasonable levels across a broader range of $\mathrm{C}$ saturation ratios, it only shifts the sharp rise in $r_{\mathrm{cr}}$ to a higher saturation ratio, and accentuates the steepness of the rise when it does occur.

In the single-pool model, the steep rise in $r_{\mathrm{cr}}$ as $\mathrm{C}$ saturation increases is unrealistic. A simple modification, adding an intermediate pool representative of microbial biomass, greatly improved the dynamics of $\mathrm{N}$ mineralization in the microbial saturation model. In this model, $r_{\mathrm{cr}}$ ranged from 23 to over 74 as the $\mathrm{C}$ saturation ratio rose above 0.9

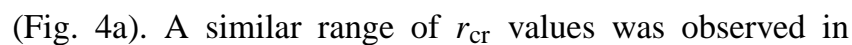
non-woody plant residues by Manzoni et al. (2010), though the range was mostly explained by $\mathrm{N}$ concentration of the residues rather than $\mathrm{C}$ saturation of the soil. Within $\mathrm{C}$ saturation ratios that would occur under a more realistic $\mathrm{C}$ input level $\left(\sim 5 \mathrm{MgCha}^{-1} \mathrm{y}^{-1}\right)$, the $r_{\mathrm{cr}}$ in the microbial saturation model ranged narrowly from 26 to 29 across a range of clay concentrations (Fig. 4b). The abiotic saturation model predicted an $r_{\text {cr }}$ of 40 based on a fixed microbial growth efficiency $(\varepsilon)$ of 0.25 . The $r_{\text {cr }}$ predicted by the two C saturation models with explicit microbial pools fall closely in line with traditional estimates of $r_{\mathrm{cr}}$ that have been developed for relatively N-rich residues (Sinsabaugh et al., 2013).

Compared to a single pool saturation model, the addition of a microbial pool to a $\mathrm{C}$ saturation model allows representing the short-term dynamics of $\mathrm{N}$ storage and turnover in microbial biomass. This improvement is achieved while preserving estimates of $\mathrm{C}$ storage and at the cost of only one additional parameter to the model. This improvement results in a model structure that can be applied to a broader set of ecological processes, including both $\mathrm{C}$ and $\mathrm{N}$ cycling at short and long timescales.

\subsection{Soil texture controls on $\mathrm{N}$ mineralization can be similar between saturation and non-saturation models}

Soil texture has direct and indirect regulating effects on $\varepsilon$ in RothC, the single-pool saturation and microbial saturation models, resulting in similar soil texture controls on $\mathrm{N}$ mineralization among the saturation and non-saturation models. RothC uses $f_{\text {clay }}$ to directly regulate $\varepsilon$ while the single-pool saturation and microbial saturation models use $f_{\text {clay }}$ to regulate $\mathrm{C}_{\mathrm{x}}$, thus affecting $\varepsilon$ (Table 1 ). In all three of these mod- els, $r_{\mathrm{cr}}$ decreases with increasing clay concentration when the pool size for $\mathrm{C}_{\mathrm{s}}$ is maintained constant (Fig. $4 \mathrm{~b}$ ). This occurs because greater fractions of $\mathrm{C}$ and $\mathrm{N}$ are transferred to stabilized pools in clay-rich soils rather than being mineralized. Early studies that demonstrated soil texture controls on $\mathrm{N}$ mineralization under a paradigm of non-saturation $\mathrm{C}$ models (Ladd et al., 1981; Van Veen et al., 1985; Schimel, 1986) are consistent with the behavior of $\mathrm{C}$ saturation models that use $\varepsilon$ to implement saturation. Therefore, $\mathrm{C}$ saturation theory may provide a mechanism to explain the effects of soil texture on $\mathrm{C}$ and $\mathrm{N}$ cycling.

\subsection{Relevance to ecosystem processes and future research}

Although the currently limited data on the links between C saturation and $\mathrm{N}$ mineralization dynamics seem to support a coupling of these processes (Castellano et al., 2012), it does not permit assessing with certainty the practical significance of such a relationship. For instance, at reasonable $\mathrm{C}$ input rates, the change in $r_{\mathrm{cr}}$ due to the effects of a clay gradient on the $\mathrm{C}$ saturation ratio is rather minor in the microbial saturation model (e.g., 26 to 29 as in Fig. 4b). The effect of C saturation on $r_{\mathrm{cr}}$ becomes much more pronounced as the saturation ratio increases above 0.5 (Fig. 4a). This level of saturation requires high $C$ inputs per unit of soil mass under the current parameterization of our model, but can be achieved in the top layer of undisturbed no-till agricultural soils or pasture lands (Mazzilli et al., 2014) or in low clay concentration soils (Castellano et al., 2012).

Given the limited but encouraging data supporting the conceptual and quantitative link between $\mathrm{C}$ saturation and $\mathrm{N}$ mineralization, we believe that further empirical research should be pursued to test the hypothesis that $\mathrm{C}$ saturation is a mechanism that controls $\mathrm{N}$ mineralization. In testing this hypothesis, it will be particularly important to design studies that utilize $\mathrm{C}$ saturation gradients across similar soil textures, as one can argue that it is difficult to separate saturation from clay concentration effects in the experiments reported in the literature (Ladd et al., 1981; Van Veen et al., 1985; Schimel, 1986; McLauchlan, 2006; Castellano et al., 2012). A more specific hypothesis generated by our work is that as C saturation ratio increases, so does the $r_{\mathrm{cr}}$ of decomposing plant residues. If this hypothesis is correct, further studies should evaluate its practical implications for managing $\mathrm{C}$ and $\mathrm{N}$ in natural and managed ecosystems. For example, a hypothesis for an applied field experiment might be that $\mathrm{N}$ mineralization dynamics are altered by $\mathrm{C}$ saturation patterns occurring in soil profiles with stratified soil organic matter, such as those in no-till agricultural systems. We also suggest conducting additional studies to verify and improve our estimation of the maximum soil $\mathrm{C}$ storage capacity $\left(\mathrm{C}_{\mathrm{x}}\right)$, as the quantitative relationship between $\mathrm{C}$ saturation and $\mathrm{N}$ mineralization is sensitive to this value and our current method of 
estimation is based on the results of only one study (Hassink and Whitmore, 1997).

Recent advances in the understanding of $\mathrm{C}$ cycling, including $\mathrm{C}$ saturation theory, need to be incorporated into a new generation of ecosystem models (Schmidt et al., 2011) as exemplified by Kemanian et al. (2011). Along with C saturation, others are active in incorporating microbial priming effects (Wutzler and Reichstein, 2008; Perveen et al., 2014) and controls on microbial C use efficiency (Allison et al., 2010; Wetterstedt and Ågren, 2011) into biogeochemical models. Perveen et al. (2014) demonstrated that $\mathrm{N}$ cycling was affected by increased fresh $\mathrm{C}$ inputs from elevated $\mathrm{CO}_{2}$ in a priming effect model. Interestingly, the definition for microbial priming proposed by Wutzler and Reichstein (2008), where "decomposition of one soil $\mathrm{C}$ pool is influenced by the dynamics of another soil C pool," also pertains to the structure of some $\mathrm{C}$ saturation models we tested in this study. Controlling microbial $\mathrm{C}$ use efficiency based on temperature has proven to be an important model feature that improves the representation of temperature effects on C cycling (Allison et al., 2010; Wetterstedt and Ågren, 2011). Given the sensitivity of $\mathrm{N}$ mineralization to $\mathrm{C}$ use efficiency that we observed in our study, temperature controls on $\mathrm{C}$ use efficiency in a model are also likely to affect a coupled $\mathrm{N}$ cycle. A next step in the development of new ecosystem models will be to test how models behave when several new $\mathrm{C}$ cycling processes are implemented simultaneously.

\section{Conclusions}

We demonstrated that different $\mathrm{C}$ saturation model structures can produce similar predictions of $\mathrm{C}$ storage, but that predictions of $\mathrm{N}$ mineralization can diverge widely. Inclusion of a microbial pool in the microbial saturation model led to more reasonable predictions of $\mathrm{N}$ mineralization compared to the single-pool saturation model. We also demonstrated that the link between $\mathrm{C}$ saturation and $\mathrm{N}$ mineralization depends on whether $\mathrm{C}$ saturation is modeled as a process regulating transfer efficiencies or transfer rates among pools in the model. In a $\mathrm{C}$ saturation model in which the saturation ratio regulates the transfer efficiency, the $\mathrm{N}$ mineralization dynamics across a soil texture gradient are similar to those of the non-saturating RothC model. These findings lead to new hypotheses about the relationship between $\mathrm{C}$ saturation and $\mathrm{N}$ mineralization that can be tested empirically, and offer a clear pathway to represent $\mathrm{C}$ saturation and $\mathrm{N}$ mineralization dynamics. 


\section{Appendix A}

Deriving the parameter $k_{\mathrm{s}}$ for the microbial saturation model that would force steady-state $C_{s}$ levels to be equivalent to the single-pool saturation model required reformulating Eq. (7) to solve $\mathrm{dC}_{\mathrm{s}} / \mathrm{d} t$ with respect to $\mathrm{C}_{\mathrm{r}}$. This is achieved by solving steady-state Eq. (6) for $k_{\mathrm{m}} \mathrm{C}_{\mathrm{m}}$ and substituting this for $k_{\mathrm{m}} \mathrm{C}_{\mathrm{m}}$ in Eq. (7). The result is Eq. (A1):

$\mathrm{dC}_{\mathrm{s}} / \mathrm{d} t=\varepsilon^{2} k_{\mathrm{r}} \mathrm{C}_{\mathrm{r}}-\left(1-\varepsilon^{2}\right) k_{\mathrm{s}} \mathrm{C}_{\mathrm{s}}$

Eqs. (A1) and (4) can equated and the turnover rate for $\mathrm{C}_{\mathrm{s}}$ in model B solved:

$k_{\mathrm{s}}=\frac{5.48 \times 10^{-5}}{\left(1-\varepsilon^{2}\right)}$.
To derive parameters for the abiotic saturation model that would force steady-state $\mathrm{C}_{\mathrm{s}}$ levels to be equivalent to steadystate $\mathrm{C}_{\mathrm{s}}$ levels in the single-pool saturation model, we reformulated Eq. (11) to solve $\mathrm{dC}_{\mathrm{s}} / \mathrm{d} t$ with respect to $\mathrm{C}_{\mathrm{r}}$. This required rearrangements of Eqs. (10) and (9) along with several substitutions. First, steady-state Eq. (9) was solved for $k_{\mathrm{m}} \mathrm{C}_{\mathrm{m}}$ and substituted into Eq. (10), which was then solved for $\mathrm{C}_{\mathrm{un}}$. The resulting equation for $\mathrm{C}_{\mathrm{un}}$ was substituted into Eq. (11), yielding

$\mathrm{dC}_{\mathrm{s}} / \mathrm{d} t=\varepsilon_{\mathrm{r}} \varepsilon k_{\mathrm{un}-\mathrm{s}} k_{\mathrm{r}} \mathrm{C}_{\mathrm{r}}-k_{\mathrm{un}}\left(1-\varepsilon_{\mathrm{r}} \varepsilon\right) k_{\mathrm{s}} C_{\mathrm{s}}$.

Eqs. (A3) and (4) can be equated and the decay rates $k_{\mathrm{un}-\mathrm{s}}$ and $k_{\mathrm{S}}$ solved:

$k_{\mathrm{un}-\mathrm{s}}=\frac{\varepsilon_{\mathrm{x}}\left(1-\mathrm{C}_{\mathrm{s}} / \mathrm{C}_{\mathrm{x}}\right)}{\varepsilon \varepsilon_{\mathrm{r}}}$
$k_{\mathrm{s}}=\frac{5.48 \times 10^{-5}}{k_{\mathrm{un}}\left(1-\varepsilon \varepsilon_{\mathrm{r}}\right)}$. 
Acknowledgements. We thank the two anonymous referees and handling editor Sébastien Fontaine for constructive comments that improved the quality of this article. This work was supported by United States Department of Agriculture AFRI grant GEOW2013-02824 and Cornell grant \#52110-9601 (Sungrant subcontract, United States Department of Transportation).

Edited by: S. Fontaine

\section{References}

Allison, S. D., Wallenstein, M. D., and Bradford, M. A.: Soil-carbon response to warming dependent on microbial physiology, Nat. Geosci., 3, 336-340, 2010.

Baldock, J. and Skjemstad, J.: Role of the soil matrix and minerals in protecting natural organic materials against biological attack, Org. Geochem., 31, 697-710, 2000.

Castellano, M., Kaye, J., Lin, H., and Schmidt, J.: Linking Carbon Saturation Concepts to Nitrogen Saturation and Retention, Ecosystems, 15, 175-187, 2012.

Eliasson, P. E. and Ågren, G. I.: Feedback from soil inorganic nitrogen on soil organic matter mineralisation and growth in a boreal forest ecosystem, Plant Soil, 338, 193-203, 2010.

Gulde, S., Chung, H., Amelung, W., Chang, C. and Six, J.: Soil Carbon Saturation Controls Labile and Stable Carbon Pool Dynamics, Soil Sci. Soc. Am. J., 72, 605-612, 2008.

Hassink, J.: Preservation of Plant Residues in Soils Differing in Unsaturated Protective Capacity, Soil Sci. Soc. Am. J., 60, 487-491, 1996.

Hassink, J.: The capacity of soils to preserve organic $\mathrm{C}$ and $\mathrm{N}$ by their association with clay and silt particles, Plant Soil, 191, 7787, 1997.

Hassink, J. and Whitmore, A. P.: A Model of the Physical Protection of Organic Matter in Soils, Soil Sci. Soc. Am. J., 61, 131-139, 1997.

Heitkamp, F., Wendland, M., Offenberger, K., and Gerold, G.: Implications of input estimation, residue quality and carbon saturation on the predictive power of the Rothamsted Carbon Model, Geoderma, 170, 168-175, 2012.

Hénin, S. and Dupuis, M.: Essai de bilan de la matière organique du sol, Ann. Agron., 15, 17-29, 1945.

Huggins, D. R., Clapp, C. E., Allmaras, R. R., Lamb, J. A., and Laysee, M. F.: Carbon dynamics in corn-soybean sequences as estimated from natural Carbon-13 abundance, Soil Sci. Soc. Am. J., 62, 195-203, 1998.

Jenkinson, D. S.: The Turnover of Organic-Carbon and Nitrogen in Soil, Philos. T. Roy. Soc. B, 329, 361-368, 1990.

Kemanian, A. R. and Stöckle, C. O.: C-Farm: A simple model to evaluate the carbon balance of soil profiles, Eur. J. Agron., 32, 22-29, 2010.

Kemanian, A. R., Manoranjan, V. S., Huggins, D. R., and Stöckle, C. O.: Assessing the usefulness of simple mathematical models to describe soil carbon dynamics, 3rd USDA Symposium on Greenhouse Gases \& Carbon Sequestration in Agriculture and Forestry, Baltimore, Maryland, 21-24 March 2005, 2005.

Kemanian, A. R., Julich, S., Manoranjan, V. S., and Arnold, J. R.: Integrating soil carbon cycling with that of nitrogen and phos- phorus in the watershed model SWAT: Theory and model testing, Ecol. Model., 222, 1913-1921, 2011.

Ladd, J. N., Oades, J. M., and Amato, M.: Microbial biomass formed from ${ }^{14} \mathrm{C},{ }^{15} \mathrm{~N}$-labelled plant material decomposing in soils in the field, Soil Biol. Biochem., 13, 119-126, 1981.

Manzoni, S. and Porporato, A.: Soil carbon and nitrogen mineralization: Theory and models across scales, Soil Biol. Biochem., 41, 1355-1379, 2009.

Manzoni, S., Jackson, R. B., Trofymow, J. A., and Porporato, A.: The global stoichiometry of litter nitrogen mineralization, Science, 321, 684-686, 2008.

Manzoni, S., Trofymow, J. A., Jackson, R. B., and Porporato, A.: Stoichiometric controls on carbon, nitrogen, and phosphorus dynamics in decomposing litter, Ecol. Monogr., 80, 89-106, 2010.

Manzoni, S., Taylor, P., Richter, A., Porporato, A., and Ågren, G. I.: Environmental and stoichiometric controls on microbial carbonuse efficiency in soils, New Phytol., 196, 79-91, 2012.

Mazzilli, S. R., Kemanian, A. R., Ernst, O. R., Jackson, R. B., and Piñeiro, G.: Priming of soil organic carbon decomposition induced by corn compared to soybean crops, Soil Biol. Biochem., 75, 273-281, 2014.

McLauchlan, K. K.: Effects of soil texture on soil carbon and nitrogen dynamics after cessation of agriculture, Geoderma, 136, 289-299, 2006.

Parton, W. J., Schimel, D. S., Cole, C. V., and Ojima, D. S.: Analysis of factors controlling soil organic matter levels in Great Plains grasslands, Soil Sci. Soc. Am. J., 51, 1173-1179, 1987.

Perveen, N., Barot, S., Alvarez, G., Klumpp, K., Martin, R., Rapaport, A., Herfurth, D., Louault, F., and Fontaine, S.: Priming effect and microbial diversity in ecosystem functioning and response to global change: a modeling approach using the SYMPHONY model., Glob. Change Biol., 20, 1174-90, 2014.

Schimel, D. S.: Carbon and nitrogen turnover in adjacent grassland and cropland ecosystems, Biogeochemistry, 2, 345-357, 1986.

Schimel, J. P. and Weintraub, M. N.: The implications of exoenzyme activity on microbial carbon and nitrogen limitation in soil: a theoretical model, Soil Biol. Biochem., 35, 549-563, 2003.

Schmidt, M. W. I., Torn, M. S., Abiven, S., Dittmar, T., Guggenberger, G., Janssens, I. A., Kleber, M., Kögel-Knabner, I., Lehmann, J., Manning, D. A. C., Nannipieri, P., Rasse, D. P., Weiner, S., and Trumbore, S. E.: Persistence of soil organic matter as an ecosystem property, Nature, 478, 49-56, 2011.

Sinsabaugh, R. L., Manzoni, S., Moorhead, D. L., and Richter, A.: Carbon use efficiency of microbial communities: stoichiometry, methodology and modelling, Ecol. Lett., 16, 930-939, 2013.

Six, J., Conant, R. T., Paul, E. A., and Paustian, K.: Stabilization mechanisms of soil organic matter: Implications for C-saturation of soils, Plant Soil, 241, 155-176, 2002.

Sørensen, L. H.: The influence of clay on the rate of decay of amino acid metabolites synthesized in soils during decomposition of cellulose, Soil Biol. Biochem., 7, 171-177, 1975.

Sørensen, L. H.: Carbon-nitrogen relationships during the humification of cellulose in soils containing different amounts of clay, Soil Biol. Biochem., 13, 313-321, 1981.

Stewart, C. E., Paustian, K., Conant, R. T., Plante, A. F., and Six, J.: Soil carbon saturation: concept, evidence and evaluation, Biogeochemistry, 86, 19-31, 2007. 
Stewart, C. E., Plante, A. F., Paustian, K., Conant, R. T., and Six, J.: Soil carbon saturation: Linking concept and measurable carbon pools, Soil Sci. Soc. Am. J., 72, 379-392, 2008.

Stewart, C. E., Follett, R. F., Wallace, J., and Pruessner, E. G.: Impact of Biosolids and Tillage on Soil Organic Matter Fractions: Implications of Carbon Saturation for Conservation Management in the Virginia Coastal Plain, Soil Sci. Soc. Am. J., 76, 12571267, 2012.

Van Veen, J. A., Ladd, J. N., and Amato, M.: Turnover of Carbon and Nitrogen through the Microbial Biomass in a Sandy Loam and a Clay Soil Incubated with $\left[{ }^{14} \mathrm{C}(\mathrm{U})\right]$ Glucose and $\left[{ }^{15} \mathrm{~N}\right]\left(\mathrm{NH}_{4}\right)_{2} \mathrm{SO}_{4}$ under Different Moisture Regimes, Soil Biol. Biochem., 17, 747-756, 1985.

Verberne, E. L. J., Hassink, J., Dewilligen, P., Groot, J. J. R., and Van Veen, J. A.: Modeling Organic-Matter Dynamics in Different Soils, Neth. J. Agr. Sci., 38, 221-238, 1990.
Wetterstedt, J. Å. M. and Ågren, G. I.: Quality or decomposer efficiency - which is most important in the temperature response of litter decomposition? A modelling study using the GLUE methodology, Biogeosciences, 8, 477-487, doi:10.5194/bg-8477-2011, 2011.

Wutzler, T. and Reichstein, M.: Colimitation of decomposition by substrate and decomposers - a comparison of model formulations, Biogeosciences, 5, 749-759, doi:10.5194/bg-5-749-2008, 2008. 